\title{
Genetic and epigenetic studies of FOXP3 in asthma and allergy
}

\author{
Cintia Rodrigues Marques ${ }^{1}$, Ryan Santos Costa', Gustavo Nunes de Oliveira Costa ${ }^{2}$, Thiago Magalhães da Silva ${ }^{2,3}$, \\ Tatiane Oliveira Teixeira ${ }^{1}$, Emília Maria Medeiros de Andrade ${ }^{1}$, Alana A. Galvão ${ }^{1}$, Valdirene Leão Carneiro ${ }^{4}$ \\ and Camila Alexandrina Figueiredo ${ }^{1 *}$
}

\begin{abstract}
Multiple factors interact to trigger allergic diseases, including individual genetic background and factors related to the environment such as exposure to allergens, air pollution and respiratory infections. The FOXP3 transcription factor is constitutively expressed in $\mathrm{CD}^{+} \mathrm{CD}_{2} 5^{+} \mathrm{FOXP3}^{+}$regulatory $\mathrm{T}$ cells (Tregs) and is critical for the maintenance of immune homeostasis. For example, FOXP3 is responsible for the suppression of the Th2 response following exposure to allergens. Studies have shown that expression of the FOXP3 gene is reduced in patients with asthma and allergies compared to healthy controls. Therefore, the impairment of FOXP3 function caused by genetic polymorphisms and/or epigenetic mechanisms may be involved in the etiology of asthma and other allergic diseases. This review discusses some aspects of the role of FOXP3 in the development of asthma and allergy, with a particular emphasis on genetic and epigenetic factors.
\end{abstract}

\section{Background}

Allergic respiratory diseases such as asthma and rhinitis are considered a serious public health problem and have an increasing prevalence in all regions of the world, regardless of the economic and social development of these regions [1]. According to the World Health Organization (WHO), each year approximately 250,000 deaths are due to asthma. and the estimated number of individuals affected by this disease has reached 300 million people worldwide [2].

Despite the increasing technological advancements of molecular biology research and the substantial exploration of the genetics and epigenetics of asthma and other allergic diseases, the immune mechanisms of such diseases remain unclear. However, in recent years, these studies have raised new interest in the regulatory molecules of the immune system [3, 4]. Some researchers have hypothesized that the genetic variations and epigenetic changes that affect molecules found in regulatory $\mathrm{T}$ cells, such as the FOXP3 gene, can cause dysfunction of regulatory $\mathrm{T}$ cells and can thus influence the development

\footnotetext{
* Correspondence: cavfigueiredo@gmail.com

${ }^{1}$ Instituto de Ciências da Saúde, Universidade Federal da Bahia, Avenida Reitor Miguel Calmon, s/n, Canela, CEP - 40110-100 Salvador, Bahia, Brazil Full list of author information is available at the end of the article
}

of immune-mediated diseases. The present review aims to provide an overview of FOXP3 role in immune regulatory processes as well as a discussion of the implications of this activity on allergic diseases, specifically asthma and allergic rhinitis.

\section{FOXP3, Asthma and Allergies}

Respiratory allergies are complex diseases that are triggered by multiple interacting factors, including an individual's genetic background and factors related to the environment, such as allergen exposure, air pollution and respiratory infection $[5,6]$. Allergic asthma is characterized by the activation of Th2 CD4+ T cells, which promotes an IgE-mediated response, activates mast cells, triggers an increase of eosinophils in the tissue and promotes bronchial hyperactivity. Upon allergen exposure and subsequent sensitization, a group of cytokines, IL-3, IL-4, IL-5, IL-9, IL-13 and GM-CSF, which are primarily Th2 type-cytokines, are released and may play a role in allergic asthma [7-9]. Recent studies have suggested that the mechanism of the Th2 response involves the epithelial production of TSLP (Thymic Stromal Lymphopoietin) during dendritic cell activation, which also leads to Th17 cell differentiation [10, 11]. IL-33 produced by endothelial and epithelial cells seems to potentiate the Th2 response, 
which worsens asthma [11]. In non-atopic asthma, skin tests are negative for specific allergens, and the serum levels of total IgE are normal or low [12,13]. In adults, such a phenotype of asthma is characterized by a poor response to bronchodilators and thus requires the prolonged use of corticosteroids and presents a more rapid decline in PFT (Pulmonary Function Testing) parameters. Symptoms of non-atopic asthma are induced by nonspecific triggers, but the pathophysiological mechanisms are not yet fully understood [14]. With the recent discovery of iNKTs cells and innate lymphoid cells, researchers have suggested a possible role for these cells in both a mechanism for increasing asthma severity $[15,16]$ and a mechanism for the non-atopic asthma phenotype [15]. In addition, severe asthma phenotypes may be associated with the presence of Th17 cells, and the production of a Th17 profile (IL-17A, IL-17 F, IL-22, and IL-21) and IL-1 $\beta$, which was shown to induce a Th17 profile and induces an increase in airway inflammation predominantly within neutrophil cells $[17,18]$. According to the hygiene hypothesis, a reduction in exposure to variety of microorganisms, improvement of hygiene and sanitation, vaccines and the advent of widespread use of antibiotics has increased the prevalence of allergic diseases worldwide, linking the lack of microbial exposures in early childhood to increased susceptibility and the development of allergic diseases [4, 17]. An extension of the hygiene hypothesis, the "Old Friends" mechanism, suggests that urbanization over the last centuries has restricted human exposure to pathogens that are considered "old friends" of humanity, such as ancestral strains of Mycobacterium tuberculosis and Helicobacter pylori, intestinal helminthes and the Hepatitis A virus. This lack of exposure may have increased the prevalence of many allergic diseases in urban populations, including asthma $[19,20]$. In this way, exposure to these "old friend" pathogens appears to be important to maturate immune cells and, more importantly, to mount a proper immune response and teach immune cells how to properly control inflammation [21]. The main mechanism whereby this can occur is through the activation of Treg cells [22] by pathogens such as viruses, bacteria and parasites [23]. There are twoTreg cell subtypes: FOXP3+ Treg cells and the Type 1 regulatory cells $(\operatorname{Tr} 1)$. The first cell subtype expresses FOXP3 and is subdivided into thymus-derived Treg cells (tTreg) and peripheral Treg cells (pTregs). The second Tr1 cell subtype does not express the FOXP3 transcription factor to exert its functions [24]. The regulatory effects of FOXP3+ Treg cells are due to its repression of IL-2 production and its induction of CTLA-4 expression. In contrast, the activity of $\operatorname{Tr} 1$ cells are dependent on IL-10 production, regardless of the FOXP3 expression levels [25-27].

Evidence suggests that the transcription factor FOXP3, which is constitutively expressed in $\mathrm{CD} 4^{+} \mathrm{CD} 25^{+} \mathrm{Foxp} 3^{+}$ regulatory $\mathrm{T}$ cells (Tregs), are critical for the maintenance of immune system homeostasis and are responsible for the suppression of Th2 responses following exposure to allergens [28] (Fig. 1).

Several studies have shown that allergic patients, including asthmatics, have lower levels of Tregs in both the bronchoalveolar lavage and peripheral blood monocytes cells (PBMC) compared with healthy subjects [29, 30].

However, these associations remain unclear. Provoost et al. 2009 showed that the numbers of peripheral blood Treg-cells were similar in control subjects and asthmatic patients [31]. Other authors have shown that patients with atopic asthma have increased levels of Treg in peripheral blood compared with healthy individuals, but not non-atopic asthmatic individuals $[4,18]$.

Also, the FOXP3 levels in asthmatic patients are controversial. Several studies have shown that FOXP3 protein expression within Treg-cells is significantly decreased in asthmatic patients $[4,31,32]$, which may result in failure of Treg cells to suppress Th proliferation and the production of cytokines observed in those patients [4, 30, 33]. However, in a recent study was described a higher FOXP3 expression in asthmatic patients than healthy individuals and the Treg cell-suppressive capacity was observed in both groups [18].

These divergence can be explained by a methodological differences between studies or because different Treg subtypes were used or because those studies were performed in the PBMC and thus represent a systemic response that may be influenced by the environment. Alternatively, the increased number of Treg cells in asthmatic patients, particularly patients with atopic asthma, may indicate a counter-regulatory mechanism that is yet not sufficient to control allergic inflammation.

Strategies to enhance the regulatory transcription factor FOXP3 have been used to treat or prevent allergic disease. The main approach to control allergy and asthma is corticosteroid therapy, either ingested or inhaled, both of which are associated with enhanced Foxp3+ expression and an increased suppressor function [34]. Recently, a novel therapeutic approach tested in mouse aimed to up-regulate FOXP3 expression in a time- and site-specific manner by administering an intra-tracheal instillation of plasmid that contains the mouse Foxp3 gene. This approach led to an attenuation of airway inflammation by reducing the Th2 immune response $[35,36]$. Thus, identifying genetically susceptible individuals in association with the development of treatment strategies would be of great relevance for managing allergic asthma.

\section{Structure and function of FOXP3}

Forkhead box (FOX) proteins constitute an evolutionarily conserved family of transcription factors with a central role not only during development but also in the 


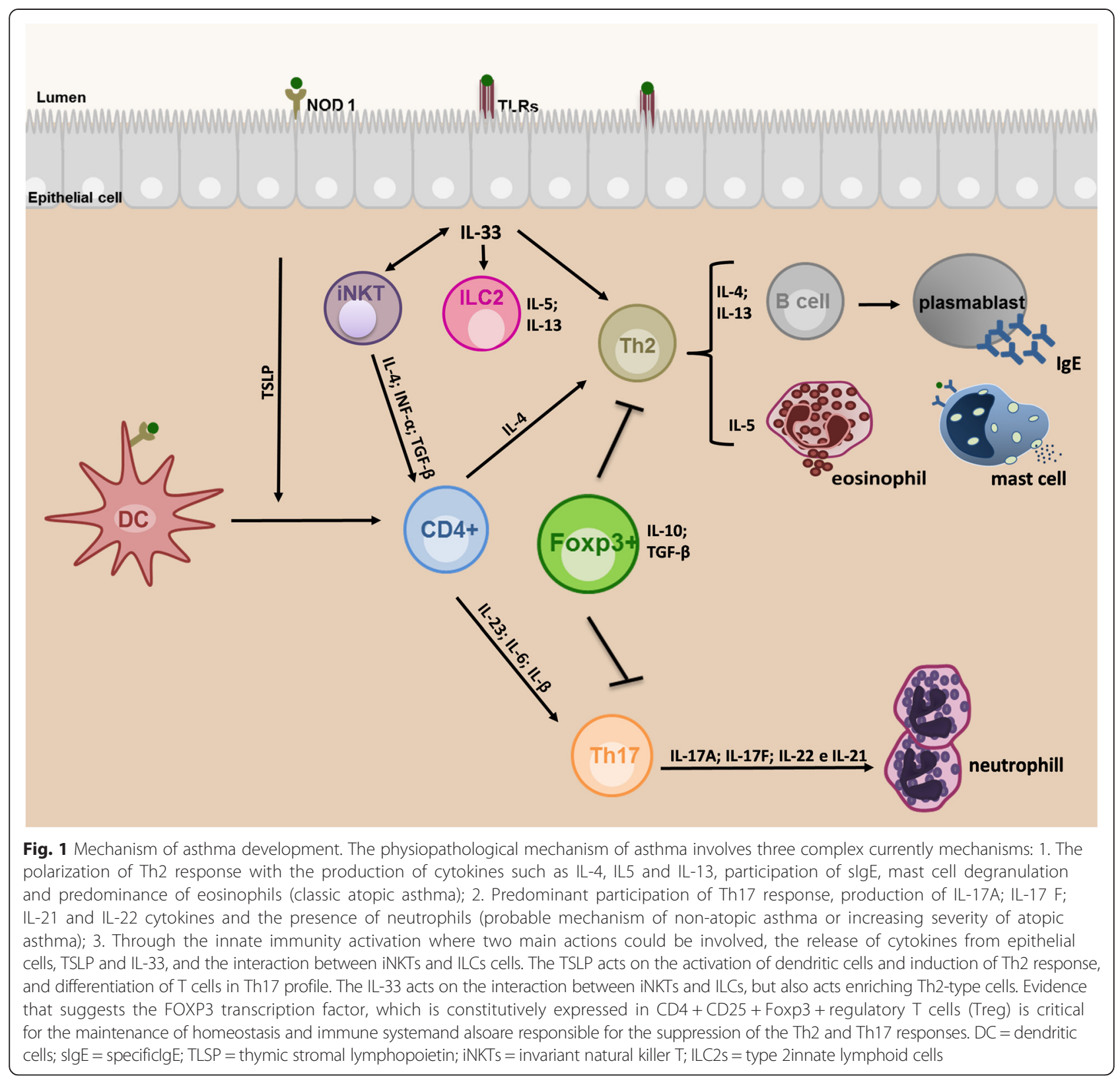

adult organism [37]. This protein is expressed by $\mathrm{T}$ cells and primarily functions to promote the differentiation of TCD4 + CD25+ cells and stimulate their suppressive activity $[38,39]$. The term, "winged helix", which is used to describe its structure, derives from a helix-turn-helix core of three $\alpha$-helices that are flanked by two loops or "wings". There is an 110-amino-acid DNA binding forkhead domain, which is highly conserved. Thus, there is a defined 3D structure and mode of DNA recognition for this forkhead family of transcription factors [38].

This protein contains 431 amino acids with four functional domains, as shown in Fig. 2. Although previous research has shown that the fragment responsible for NFAT inhibition is in the N-terminal, another study demonstrated that removal of the FOXP3 C-terminal prevents NFAT binding [40].

The expression of this transcription factor in $\mathrm{T}$ cells is related to the proliferation of regulatory $\mathrm{T}$ cells, which exert their suppressive activity on $\mathrm{T}$ helper cells to regulate the inflammatory response [41].

The role of FOXP3 in Treg cells has been demonstrated in studies that suppress the function of this gene and through adoptive transfer experiments. Several authors have shown that after the knockout of FOXP3, Treg cells lose their suppressive activity and start to produce IL-2 and Th1 cytokines. Similar to these findings, the adoptive transfer of FOXP3 retrieves the regulatory function of $\mathrm{T}$ cells and suppresses lymphoproliferative activity [42-44]. 


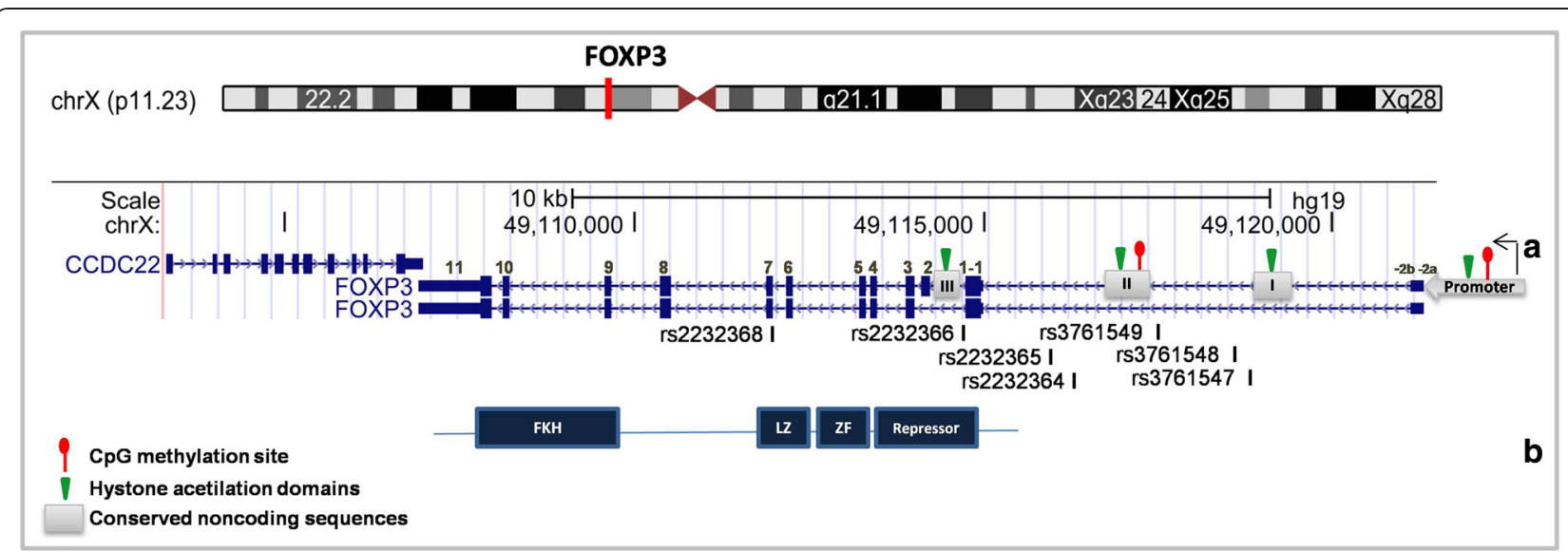

Fig. 2 Schematic diagram of the FOXP3 gene (a), protein (b) and X Chromosome. The figure shows two isoforms of the gene (with difference in exon 2) and some SNPs cited in the text. ZF: zinc finger domain, LZ: leucine zipper domain, and FKH fork-head domain.. The chromosome and gene schematic diagram was modified from NCBI Reference Sequence (RefSeq)

The importance of FOXP3 for immune system function was demonstrated in scurfy mice with lymphoproliferative disease and an X-linked condition that was caused by a mutation in FOXP3 that deletes the Cterminal domain. These animals are deficient in the production of regulatory $\mathrm{T}$ cells and present with clinical symptoms, such as exfoliative dermatitis, weight loss, presence of auto-antibodies, lymphadenopathy and lymphocytic infiltrates, which lead to animal death in approximately 3 weeks [45].

Many studies have investigated the specific domains and, consequently, the function of FOXP3. Mutations in the forkhead domain at amino acid positions 415 and 416 abolished nuclear migration of FOXP3. Mutations in the leucine zipper domain cause a loss of dimerization and thus reduce FOXP3 binding to promoter regions [46, 47].

FOXP3 is critically important for regulating the immune system and can suppress NFAT function, thereby inhibiting NFAT complex formation with AP-1 and inflammatory pathway activation. NFAT is bound in its promoter region by FOXP3, which primarily serves to down-regulate IL- 2 and IL-4 and to up-regulate CTL-4 and CD25 [48]. FOXP family members can form dimmers and activate transcription [49]. Members of this subfamily include FOXP1, FOXP2, FOXP3 AND FOXP4. FOXP1, FOXP2 and FOXP4 are expressed in gut, brain and lung and appear to have a role in embryogenesis that is maintained in adults [49]. FOXP1 and FOXP2 activity is found in the immune system $[49,50]$. The co-expression and heterodimer formation of FOXP1/FOXP3 has been reported. FOXP1 is present in both CD4+CD25+ and CD4 + CD25- T cells, whereas FOXP3 is expressed only in CD4 + CD25+ T cells. In mice with IPEX syndrome, the depletion of E251 impaired the heterodimerization of FOXP3 with FOXP1, thus suggesting a role for such heterodimerization in suppressive immune activity [50].
The role of FOXP3 polymorphism in asthma and allergic diseases

The human FOXP3 gene is located on the X-chromosome (Xp11.23), is $1296 \mathrm{bp}$ in size, and contains 11 coding exons and 3 noncoding exons. The FOXP3 gene belongs to a family of molecular complexes that are $\sim 600 \mathrm{kd}$ all together and includes histone deacetylases and acetyltransferases, as well as other transcription factors such as RUNX1 and NFAT1 [48, 51, 52]. Fig. 2 shows a schematic diagram of the FOXP3 gene.

As observed in Fig. 2, two upstream 5' noncoding exons ( $-2 \mathrm{a}$ and $-2 \mathrm{~b})$ are separated by 640 base pairs and are linked at the second noncoding exon $(-1)$. The $-2 b$ and -1 exons are separated by five hundred base pairs and have several cis-regulated elements $[53,54]$. The FOXP3 gene has more than a hundred single nucleotide polymorphisms (SNPs), nearly twenty of which have been studied for association with different diseases [55-58].

SNPs are the most common variations in the genome and are responsible for individual phenotypic differences. The coding sequences of genes are often conserved, but the presence of SNPs or genetic mutations may be related to the susceptibility to complex diseases. The role of host genetic factors in the etiology of complex diseases is generally studied using Genome-Wide Association Studies (GWAS) or Candidate Gene Studies. Many GWAS have investigated the influence of genetic polymorphisms on the development allergic diseases [59-61], but few studies have included the X chromosome because it is difficult to analyze [62]. The $\mathrm{X}$ chromosome contains more than 300,000 SNPs on 2300 genes, almost all of which encode proteins, such as FOXP3 [63, 64]. GWAS of asthma have successful identified genetic susceptibility; however, little information about the $\mathrm{X}$ chromosome has been reported, and no information about the association of FOXP3 SNPs 
on allergic diseases has emerged [59-61]. A notable exception is the Moffatt et al. 2010 study, which analyzed the $\mathrm{X}$ chromosome in populations with predominant European ancestry but reported no statistically significant association signals [65]. However, it is important to note that $\mathrm{X}$ chromosomal variants are often underrepresented in genotyping platforms compared with autosomal chromosomes [66]. The fact is that the analysis of SNPs within the $\mathrm{X}$ chromosome can provide important information regarding genetic factors associated with diseases and should not be neglected. GWAS are the most powerful approach to identify the genetic risk for asthma, but candidate gene studies are the most common, and the results of these studies on FOXP3 are discussed here.

Recently, the FOXP3 gene has been investigated in association studies for many diseases [55-57]. Mutations in this gene may be associated with the development of Immune dysregulationpolyendocrinopathy and enteropathy $\mathrm{X}$-linked (IPEX) syndrome, a rare and fatal pediatric condition. Bennett et al. 2001 identified a mutation in the FOXP3 gene in patients with IPEX who exhibited aggressive autoimmune features [45]. This finding suggests that the genetic variations in FOXP3 gene may be associated with $\mathrm{T}$ cell dysfunction. Thus, host genetic factors that affect FOXP3 can determine differences in susceptibility to allergic diseases such as asthma.

Over the last few years, polymorphisms in this gene have been evaluated in association studies for several allergies [67-69], but few studies in asthma were conducted. Therefore, we here discuss the major findings concerning the FOXP3 gene in association studies for asthma and other allergic conditions. Table 1 presents all of the SNPs in the FOXP3 gene that have been published to date for asthma and allergic diseases, including the sample size.

\section{rs3761548}

The rs3761548 is located in the intronic region of the FOXP3 gene. It is the most studied SNP for FOXP3 and has been associated with several diseases, including many allergic conditions.

Bottema et al. 2009 studied the association of this SNP with atopy and observed no significant association with IgE levels; however, an association was found to food sensitivity to egg allergens (OR: 0.5 ; $95 \%$ CI $0.3-1.0$ ) [67]. In addition, another study reported significant interaction $(p<0.01)$ between SNPs in FOXP3-IL2R genes and IgE for eggs and asthma [70].

In association studies with allergic rhinitis (AR), Hassannia 2011 reported that the AC genotype for this rs3761548allele was protective for AR in females (OR, 0.16; $95 \%$ CI 0.05-0.5) but that the C allele was protective (OR: 0.47 ; $95 \%$ CI $0.22-0.99$ ) for AR in males [71]. However, a study conducted in Hungary found protection $p<0.05$ for allergic rhinitis only in females who carried the AA genotype [68]. A similar finding was reported in another study that found a positive association (OR: 3.12; $95 \%$ CI 1.218.04) between the heterozygous genotype and AR [69]. In a haplotype analysis, Zhang 2012 found that the diplotype rs3761548-rs4824747 with "AG" was associated (OR: 1.75 ; 95 \% CI 1.05-2.92) with a significantly increased risk of AR [72]. In addition to these findings, Hassannia et al. 2011 reported that women with genotype $\mathrm{AC}$ and $\mathrm{CC}$ showed reduced levels of total serum IgE. In men, the presence of the $\mathrm{C}$ allele was associated with a reduction in the total serum IgE levels [71].

Thus, this polymorphism appears to contribute to the risk of allergic disease, but further studies are needed to determine its effects on asthma.

\section{rs2232365}

This SNP is located in the intronic region of the FOXP3 gene. Although it has been included in several studies of different diseases, few studies on AR have included it. No association of this SNP was found with either AR $[69,71,72]$ or the levels of IgE and peripheral blood eosinophil [71]. The same results were observed for association using haplotype analysis [72]. These data suggest that rs2232365 likely does not play an important role in $\mathrm{AR}$, but its roles in other allergic diseases, such as asthma and atopy remain unclear.

\section{rs6609857}

The rs6609857SNP is located near the 3' UTR region of the FOXP3 gene, and although it is characterized as part of the FOXP3 gene, its genomic physical position is located in the $C C D C 22$ gene (coiled-coil domain containing 22). This marker has been investigated in the context of asthma, allergy and IgE, but none of these studies have implicated rs6609857 as a risk factor for these outcomes [67].

\section{Other SNPs}

The SNPs rs2294019 and rs5906761 were associated (OR: 3.9; 95 \% CI 1.2-12.5 and OR: 4.1; 95 \% CI 1.115.4, respectively) with a risk to egg sensitivity only in females [67]. The heterozygote genotype for rs3761547 was a risk factor for allergic rhinitis, and this association was reproduced in gene-gene interaction analysis with rs3761548 [69, 72].

Taken together, these results all show that polymorphism in FOXP3 gene is associated with some allergic disease, but its contribution to asthma has been poorly studied. Moreover, there is heterogeneity in the sample size and population, which makes it difficult to compare the different studies. Thus, more studies are needed to 
Table 1 FOXP3 SNPs investigated for association with asthma and allergy

\begin{tabular}{|c|c|c|c|c|c|c|c|}
\hline SNP & Genomic Position & Alleles & Function & Diseases & N (cases/controls) & Country & Reference \\
\hline \multirow[t]{10}{*}{ rs3761548 } & $49,261,784$ & $\mathrm{~A} / \mathrm{C}$ & Intron & Atopy & $3062^{*}$ & The Netherlands & Bottema, 2009 \\
\hline & & & & Allergic rhinitis & 395 & Hungary & Fodor, 2010 \\
\hline & & & & & $(178 / 217)$ & & \\
\hline & & & & Asthma & $3062^{*}$ & The Netherlands & Bottema, 2010 \\
\hline & & & & Allergic rhinitis & 384 & China & Zhang, 2009 \\
\hline & & & & & $(193 / 191)$ & & \\
\hline & & & & Allergic rhinitis & 318 & Iran & Hassannia, 2011 \\
\hline & & & & & $(153 / 165)$ & & \\
\hline & & & & Allergic rhinitis & 708 & China & Zhang, 2012 \\
\hline & & & & & (378/330) & & \\
\hline \multirow[t]{6}{*}{ rs2232365 } & $49,259,429$ & $A / G$ & Intron] & Allergic rhinitis & 384 & China & Zhang, 2009 \\
\hline & & & & & $(193 / 191)$ & & \\
\hline & & & & Allergic rhinitis & 708 & China & Zhang, 2012 \\
\hline & & & & & $(378 / 330)$ & & \\
\hline & & & & Allergic rhinitis & 318 & Iran & Hassannia, 2011 \\
\hline & & & & & $(153 / 165)$ & & \\
\hline \multirow[t]{2}{*}{ rs6609857 } & $49,245,158$ & $C / T$ & $3^{\prime}$ UTR & Asthma & $3062^{*}$ & The Netherlands & Bottema, 2010 \\
\hline & & & & Atopy & $3062^{*}$ & The Netherlands & Bottema, 2009 \\
\hline \multirow[t]{2}{*}{ rs2232368 } & $49,255,822$ & $A / G$ & Intron & Allergic rhinitis & 384 & China & Zhang, 2009 \\
\hline & & & & & $(193 / 191)$ & & \\
\hline \multirow[t]{2}{*}{ rs2232366 } & $49,258,209$ & $\mathrm{G} / \mathrm{T}$ & Intron & Allergic rhinitis & 384 & China & Zhang, 2009 \\
\hline & & & & & $(193 / 191)$ & & \\
\hline \multirow[t]{2}{*}{ rs2232364 } & $49,259,888$ & $\mathrm{~A} / \mathrm{C} / \mathrm{G} / \mathrm{T}$ & Intron & Allergic rhinitis & 384 & China & Zhang, 2009 \\
\hline & & & & & $(193 / 191)$ & & \\
\hline rs3761549 & $49,260,888$ & $\mathrm{C} / \mathrm{T}$ & Intron & Atopy & $3062^{*}$ & The Netherlands & Bottema, 2009 \\
\hline \multirow[t]{2}{*}{ rs3761547 } & $49,262,004$ & $A / G$ & Intron & Allergic rhinitis & 384 & China & Zhang, 2009 \\
\hline & & & & & $(193 / 191)$ & & \\
\hline \multirow[t]{2}{*}{ rs2869211 } & $49,264,409$ & $A / T$ & Intron & Allergic rhinitis & 384 & China & Zhang, 2009 \\
\hline & & & & & $(193 / 191)$ & & \\
\hline
\end{tabular}

Cases and controls were not shown for all studies (*) because some studies use different phenotypes and analyze sex and age separately

evaluate the role of FOXP3 polymorphisms in allergic diseases.

\section{Epigenetic regulation of FOXP3 in asthma}

The constitutive expression of FOXP3 is required for the immunosuppressive function of Treg cells. In addition to the activity of trans-acting factors, epigenetic modifications play a central role in maintaining the stability of Treg cells. Epigenetics refers to changes in gene expression that are not caused by changes in the DNA sequence. Epigenetic mechanisms include DNA methylation and histone modification. DNA methylation occurs predominantly at CpG nucleotides and is catalyzed by DNA methyltransferases (DNMts). DNA methylation can inhibit gene expression directly by precluding the binding of specific transcription factors in promoter region of genes, or indirectly by promoting the recruitment of methyl-CpGbinding domain (MBD) proteins and their associated histone-modifying and chromatin-remodeling complexes [73]. Histones are protein constituents of nucleosomes that are subjected to different post-translational modifications in their $\mathrm{N}$-terminal tails, including acetylation, methylation, phosphorylation, ubiquitination, SUMOylation and ADPribosylation [74]. Histone acetylation is catalyzed by histone acetyltransferase, and acetyl groups are removed by histone deacetylases (HDACs). Whereas histone acetylation results in open chromatin that permits recruitment of transcriptional machinery, deacetylation catalyzed by HDACs leads to the formation of closely compact chromatin that inhibits transcription.

Four FOXP3 regions are susceptible to epigenetic modification in conserved noncoding sequences of DNA 
(CNS). These regions are the promoter region, enhancers $[1,2]$ and the pioneer element region (Fig. 2). In the promoter region, CpG motifs are partially methylated in CD4+ naive cells and demethylated in regulatory T-cells. The first enhancer region, which is formed by CNS-1, is susceptible to histone acetylation, but has no CpG motifs. This region is rich in linking sites for NFAT and Smad3 [75]. The second enhancer region is formed by CNS-2 and is known as the Treg-cell-specific demethylation region (TSDR) $[76,77]$. The CpG motifs in this region are methylated in conventional $\mathrm{T}$ cells and demethylated in natural Tregs. Additionally, histones near this region are acetylated in thymus-derived Treg cells [78]. The pioneer element region in FOXP3 is responsible for regulating the size, composition and stability of $\mathrm{T}$ regulatory cell family members [79]. Specifically, the CNS-3 enhances the frequency of Treg cell generation in both, thymus and in the periphery [79]. Chromatin modification marks at this site are permissive in Treg. In addition, the mono- and di-methylation patterns observed in Treg-precursors are absent in CNS-1 and CNS-2, which allows transcription factors to bind preferentially to this area instead of binding to CNS-1 or CNS-2 [78].

Several lines of evidence show that epigenetic changes in the FOXP3 locus of Treg cells influence the asthma phenotypes. A summary of these studies, including their sample sizes, is shown in Table 2.

Nadeau et al. reported that among individuals who were exposed to both high and low levels of environmental pollutants, FOXP3 mRNA expression and Treg cell function were reduced in children with asthma compared to children without asthma. Accordingly, the methylation of $\mathrm{CpG}$ islands located in the promoter and in intronic regions of FOXP3 in Treg cells was higher in asthmatics relative to children without asthma, with a greater effect being observed in children who were exposed to high levels of pollution. The percentage of methylated CpG motifs in asthmatic and non-asthmatic individuals was $\sim 60 \%$ and $\sim 45 \%, p<0.01$, respectively [80]. The hypermethylation of FOXP3 in buccal cells was associated with a risk of persistent asthma and wheezing in childhood (OR: 3.05; 95 \% CI 1.54-6.05). In addition, a positive correlation was observed between FOXP3 methylation and exposure to chronic diesel exhaust particles (DEP) (4.01 \%, 95 \% CI 1.83-6.18\%; increase in FOXP3 methylation per interquartile range increase in estimated DEP exposure) [81]. A study of monozygotic twins (MZT) pairs that were discordant for asthma found a decrease in FOXP3 protein expression and impaired Treg function in the asthmatic twin, both of which were associated with increased levels of CpG methylation within the FOXP3 locus. CpG sites within FOXP3 were almost six times more methylated in the asthmatic MZT vs the non-asthmatic MZT, $p<0.001$. Furthermore, these effects were increased by current exposure to second-hand smoke (SHS) [82]. In addition, SHS and air pollution exposure, which have been associated with an increased prevalence and severity of asthma, were positively associated with hypermethylation and the decreased expression of FOXP3 in Tregs. The mean \% CpG methylation of FOXP3 among SHS-exposed vs non-SHS-exposed was $74.60 \%$ vs $54.44 \%$, respectively, $p<0.05$, and the mean transcription levels of FOXP3 among SHS-exposed and non-SHS-exposed were 0.75 and 3.29, respectively, $p<0.05$ [83]. These results suggest that exposure to certain environmental factors, such as pollutants, may induce epigenetic modifications in the FOXP3 locus with a consequently increased risk of asthma.

Lluis et al. showed that farm milk consumption was inversely associated with doctor-diagnosed asthma at age 4 years (OR: 0.26 ; 95 \% CI 0.08-0.88) and that FOXP3 demethylation at the TSDR region was consistently higher, although no significant, in whole blood of children who had consumed farm milk (median differences for all CpGs, $p=0.08$ ). In addition, protection against asthma by farm milk exposure was partially mediated by Treg cells [84]. However, no difference in the FOXP3 methylation status was observed in children with farm exposure in general compared to those without exposure [85]. This latter result suggests that the effect of farm environment on the epigenetic modification of FOXP3 is specific to the type of exposures and may not be detected, depending on the exposure assessment. Interestingly, a recent study showed that patients with atopic

Table 2 FOXP3 epigenetic studies investigated for association with asthma and allergy

\begin{tabular}{|c|c|c|c|c|}
\hline Author(s) & Year & n (cases/controls) & Epigenetic marker analyzed & Cell population analysed \\
\hline Nadeau et al. & 2010 & $32(16 / 16)$ & CpG methylation & Treg cells (CD4 ${ }^{+} \mathrm{CD} 25^{\text {hi }} \mathrm{CD} 127^{\text {lo }}$ ) and effector T (Teff) cells (CD4 $\left.{ }^{+} \mathrm{CD} 25^{\mathrm{lo} / \mathrm{neg}}\right)$ \\
\hline Brunst et al. & 2013 & $71(15 / 56)$ & CpG methylation & Buccal cells in saliva \\
\hline Runyon et al. & 2012 & $42(21 / 21)$ & CpG methylation & Treg cells $\left(\mathrm{CD} 4^{+} \mathrm{CD} 25^{\mathrm{hi}} \mathrm{CD} 127^{\mathrm{lo} / \mathrm{neg}}\right)$ and Teff $\mathrm{CD} 4^{+} \mathrm{CD} 25^{\text {neg }}$ \\
\hline Kohli et al. & 2012 & $102(37 / 65)$ & CpG methylation & Treg cells $\left(\mathrm{CD} 4^{+} \mathrm{CD} 25^{\text {hi }} \mathrm{CD} 127^{\mathrm{lo}}\right)$ and Teff $\mathrm{CD} 4^{+} \mathrm{CD} 25^{\text {neg }}$ \\
\hline Lluis et al. & 2014 & 43 & CpG methylation & Whole blood \\
\hline Michel et al. & 2013 & $95(45 / 50)$ & CpG methylation & Cord blood and whole blood \\
\hline
\end{tabular}


asthma had a trend-wise higher average level of histone $\mathrm{H} 3$ acetylation in the FOXP3 promoter region compared with healthy controls, although this difference was not statistically significant $(p=0.07, n=26$, for the mean difference in H3 acetylation between atopic asthma cases and controls) [86]. Because histone acetylation is associated with increased gene activity, an increased number of Treg cells would be expected in patients with atopic asthma, which was reported recently in a study conducted in this same population [18]. These results suggest that the status of Treg cells may differ according to the asthma phenotype considered (allergic or non-allergic).

Finally, the administration of 5-azacytidine (Aza), a DNA methyltransferase inhibitor, to chicken ovalbumin (OVA)-sensitized mice decreased airway hyperreactivity, pulmonary eosinophilia, the levels of OVA-specific IgG1 and IgE in serum, and secretion of Th2 cytokines from OVA-stimulated splenocytes in a dose-dependent manner. Furthermore, the number of Treg cells was remarkably increased in Aza-treated mice compared with sensitized control mice [87]. These data indicate that epigenetic regulation of Treg might contribute to the modulation of asthma-induced airway inflammation, which opens the possibility for treating allergic asthma and other allergic diseases by using epigenetic therapeutic agents.

\section{Conclusions}

Polymorphisms in the FOXP3 gene have been associated with some allergic diseases but the contribution of these polymorphisms to asthma development has been poorly studied. Several lines of evidence point to the involvement of epigenetic changes in the FOXP3 locus of Treg cells in asthma phenotypes. Further investigation will be important to clarify the role of FOXP3 polymorphisms and epigenetics mechanisms on the risk of asthma and other allergic diseases. Furthermore, genome-wide analyses of epigenetic markers in Treg cells are needed to enrich our ability to develop epigenetic therapeutic approaches to asthma and allergies.

\section{Competing interests}

The authors declare that they have no competing interests.

\begin{abstract}
Authors' contributions
CRM participated in drafting and revising the manuscript, and participated in the preparation of the figures. RSC participated in drafting the manuscript. GNOC: participated in drafting the manuscript and preparing the figures. TMS participated in drafting the manuscript. TOT participated in drafting the manuscript. EMMA participated in drafting the manuscript and preparing the figures. AAG participated in drafting the manuscript. VLC participated in drafting the manuscript. CAF participated in drafting and revising the manuscript, and gave final approval of the version to be published. All authors have read and approve of the final manuscript.
\end{abstract}

Authors' information

Not applicable.

\section{Author details}

${ }^{1}$ Instituto de Ciências da Saúde, Universidade Federal da Bahia, Avenida Reitor Miguel Calmon, s/n, Canela, CEP - 40110-100 Salvador, Bahia, Brazil. ${ }^{2}$ Instituto de Saúde Coletiva, Universidade Federal da Bahia, Salvador, Brazil. ${ }^{3}$ Departamento de Ciências Biológicas, Universidade Estadual do Sudoeste da Bahia, Jequié, Brazil. "Departamento de Ciências da Vida, Universidade do Estado da Bahia, Salvador, Brazil.

Received: 13 March 2015 Accepted: 24 September 2015

Published online: 20 October 2015

\section{References}

1. Martinez FD. Trends in asthma prevalence, admission rates, and asthma deaths. Respir Care. 2008:53(5):561-5. discussion 565-567.

2. $\mathrm{WHO}$, editor. Global surveillance, prevention and control of chronic respiratory diseases: a comprehensive approach. Switzerland: WHO; 2007.

3. Kinoshita T, Baatjes A, Smith SG, Dua B, Watson R, Kawayama T, et al. Natural regulatory $T$ cells in isolated early responders compared with dual responders with allergic asthma. J Allergy Clin Immunol. 2014;133(3):696-703.

4. Lin YL, Shieh CC, Wang JY. The functional insufficiency of human CD4 + CD25 high T-regulatory cells in allergic asthma is subjected to TNF-alpha modulation. Allergy. 2008;63(1):67-74.

5. Bachert C, Jorissen M, Bertrand B, Khaltaev N, Bousquet J. Allergic Rhinitis and its impact on asthma update (ARIA 2008). Belg Perspect B-ENT. 2008;4(4):253-7.

6. Scholtens S, Postma DS, Moffatt MF, Panasevich S, Granell R, Henderson AJ, et al. Novel childhood asthma genes interact with in utero and early-life tobacco smoke exposure. J Allergy Clin Immunol. 2014;133(3):885-8.

7. Barnes PJ. Immunology of asthma and chronic obstructive pulmonary disease. Nat Rev Immunol. 2008:8(3):183-92.

8. Finkelman FD, Hogan SP, Hershey GK, Rothenberg ME, Wills-Karp M. Importance of cytokines in murine allergic airway disease and human asthma. J Immunol. 2010;184(4):1663-74.

9. Holgate ST. Innate and adaptive immune responses in asthma. Nat Med. 2012;18(5):673-83.

10. Ziegler SF, Artis D. Sensing the outside world: TSLP regulates barrier immunity. Nat Immunol. 2010;11(4):289-93.

11. Nabe T. Interleukin (IL)-33: new therapeutic target for atopic diseases. J Pharmacol Sci. 2014;126(2):85-91.

12. Souza da Cunha S, Barreto ML, Fiaccone RL, Cooper PJ, Alcantara-Neves NM, Simoes Sde M, et al. Asthma cases in childhood attributed to atopy in tropical area in Brazil. Rev Panam Salud Publica. 2010;28(6):405-11.

13. Pereira MU, Sly PD, Pitrez PM, Jones MH, Escouto D, Dias AC, et al. Nonatopic asthma is associated with helminth infections and bronchiolitis in poor children. Eur Respir J. 2007;29(6):1154-60.

14. Kim HY, DeKruyff RH, Umetsu DT. The many paths to asthma: phenotype shaped by innate and adaptive immunity. Nat Immunol. 2010;11(7):577-84

15. Yu S, Kim HY, Chang YJ, Dekruyff RH, Umetsu DT. Innate lymphoid cells and asthma. J Allergy Clin Immunol. 2014;133(4):943-50. quiz 951.

16. Barnig C, Cernadas M, Dutile S, Liu X, Perrella MA, Kazani S, et al. Lipoxin A4 regulates natural killer cell and type 2 innate lymphoid cell activation in asthma. Sci Transl Med. 2013;5(174):174ra126.

17. Newcomb DC, Peebles Jr RS. Th17-mediated inflammation in asthma. Curr Opin Immunol. 2013;25(6):755-60.

18. Raedler D, Ballenberger N, Klucker E, Bock A, Otto R, Prazeres da Costa O, et al. Identification of novel immune phenotypes for allergic and nonallergic childhood asthma. J Allergy Clin Immunol. 2015;135(1):81-91.

19. Rook GA, Brunet LR. Microbes, immunoregulation, and the gut. Gut. 2005;54(3):317-20.

20. Rook GA, Lowry CA, Raison CL. Microbial 'Old Friends', immunoregulation and stress resilience. Evol Med Public Health. 2013;2013(1):46-64.

21. Lloyd CM, Hawrylowicz CM. Regulatory T cells in asthma. Immunity. 2009;31(3):438-49.

22. Hawrylowicz CM, O'Garra A. Potential role of interleukin-10-secreting regulatory T cells in allergy and asthma. Nat Rev Immunol. 2005;5(4):271-83.

23. Figueiredo CA, Alcantara-Neves NM, Amorim LD, Silva NB, Carvalho LC, Cooper PJ, et al. Evidence for a modulatory effect of IL-10 on both Th1 and Th2 cytokine production: the role of the environment. Clin Immunol. 2011;139(1):57-64. 
24. Abbas AK, Benoist C, Bluestone JA, Campbell DJ, Ghosh S, Hori S, et al. Regulatory T cells: recommendations to simplify the nomenclature. Nat Immunol. 2013;14(4):307-8.

25. Fantini MC, Becker C, Monteleone G, Pallone F, Galle PR, Neurath MF Cutting edge: TGF-beta induces a regulatory phenotype in CD4 + CD25- T cells through Foxp3 induction and down-regulation of Smad7. J Immunol. 2004;172(9):5149-53.

26. Sakaguchi S. Naturally arising CD4+ regulatory t cells for immunologic selftolerance and negative control of immune responses. Annu Rev Immunol. 2004:22:531-62.

27. Levings MK, Gregori S, Tresoldi E, Cazzaniga S, Bonini C, Roncarolo MG. Differentiation of $\operatorname{Tr} 1$ cells by immature dendritic cells requires $\mathrm{IL}-10$ but not CD25 + CD4+ Tr cells. Blood. 2005;105(3):1162-9.

28. Pellerin L, Jenks JA, Bégin P, Bacchetta R, Nadeau KC. Regulatory T cells and their roles in immune dysregulation and allergy. Immunol Res. 2014;58(2-3):358-68.

29. Wang LH, Lin YH, Yang J, Guo W. Insufficient increment of CD4 + CD25+ regulatory $T$ cells after stimulation in vitro with allergen in allergic asthma. Int Arch Allergy Immunol. 2009;148(3):199-210.

30. Hartl D, Koller B, Mehlhorn AT, Reinhardt D, Nicolai T, Schendel DJ, et al. Quantitative and functional impairment of pulmonary CD4 + CD25hi regulatory T cells in pediatric asthma. J Allergy Clin Immunol. 2007;119(5):1258-66.

31. Provoost $S$, Maes T, van Durme YM, Gevaert P, Bachert C, Schmidt-Weber CB, et al. Decreased FOXP3 protein expression in patients with asthma. Allergy. 2009;64(10):1539-46.

32. Luo ZX, Liu EM, Deng B, Li X, Chen KH, Wang $L$, et al. Role of Foxp3 expression and CD4 + CD25+ regulatory T cells on the pathogenesis of childhood asthma. Zhonghua Er Ke Za Zhi. 2006:44(4):267-71.

33. Ling EM, Smith T, Nguyen XD, Pridgeon C, Dallman M, Arbery J, et al. Relation of CD4 + CD25+ regulatory T-cell suppression of allergen-driven T-cell activation to atopic status and expression of allergic disease. Lancet. 2004;363(9409):608-15.

34. Karagiannidis C, Akdis M, Holopainen P, Woolley NJ, Hense G, Rückert B, et al. Glucocorticoids upregulate FOXP3 expression and regulatory $T$ cells in asthma. J Allergy Clin Immunol. 2004;114(6):1425-33.

35. Mays LE, Ammon-Treiber S, Mothes B, Alkhaled M, Rottenberger J, MüllerHermelink ES, et al. Modified Foxp3 mRNA protects against asthma through an IL-10-dependent mechanism. J Clin Invest. 2013;123(3):1216-28.

36. Zhang M, Qian YY, Chai SJ, Liang ZY, Xu Q, Wu ZQ, et al. Enhanced local Foxp3 expression in lung tissue attenuates airway inflammation in a mouse model of asthma. J Asthma. 2014;51(5):451-8.

37. Benayoun BA, Caburet $\mathrm{S}$, Veitia RA. Forkhead transcription factors: key players in health and disease. Trends Genet. 2011;27(6):224-32.

38. Carlsson P, Mahlapuu M. Forkhead transcription factors: key players in development and metabolism. Dev Biol. 2002;250(1):1-23.

39. Fontenot JD, Gavin MA, Rudensky AY. Foxp3 programs the development and function of CD4 + CD25+ regulatory T cells. Nat Immunol. 2003:4(4):330-6.

40. Heinze E, Chan G, Mory R, Khavari R, Alavi A, Chung SY, et al. Tumor suppressor and T-regulatory functions of Foxp3 are mediated through separate signaling pathways. Oncol Lett. 2011;2(4):665-8.

41. Hori S, Nomura T, Sakaguchi S. Control of regulatory T cell development by the transcription factor Foxp3. Science. 2003;299(5609):1057-61.

42. Khattri R, Cox T, Yasayko SA, Ramsdell F. An essential role for Scurfin in CD4 +CD25+ T regulatory cells. Nat Immunol. 2003;4(4):337-42.

43. Park JH, Ko JS, Shin Y, Cho JY, Oh HA, Bothwell AL, et al. Intranuclear interactomic inhibition of FoxP3 suppresses functions of Treg cells. Biochem Biophys Res Commun. 2014;451(1):1-7.

44. Williams LM, Rudensky AY. Maintenance of the Foxp3-dependent developmental program in mature regulatory $T$ cells requires continued expression of Foxp3. Nat Immunol. 2007;8(3):277-84.

45. Bennett $C L$, Christie J, Ramsdell F, Brunkow ME, Ferguson PJ, Whitesell L, et al. The immune dysregulation, polyendocrinopathy, enteropathy, X-linked syndrome (IPEX) is caused by mutations of FOXP3. Nat Genet. 2001;27(1):20-1.

46. Chae WJ, Henegariu O, Lee SK, Bothwell AL. The mutant leucine-zipper domain impairs both dimerization and suppressive function of Foxp3 in T cells. Proc Natl Acad Sci U S A. 2006;103(25):9631-6.

47. Lopes JE, Torgerson TR, Schubert LA, Anover SD, Ocheltree EL, Ochs HD, et al. Analysis of FOXP3 reveals multiple domains required for its function as a transcriptional repressor. J Immunol. 2006;177(5):3133-42.
48. Wu Y, Borde M, Heissmeyer V, Feuerer M, Lapan AD, Stroud JC, et al. FOXP3 controls regulatory $T$ cell function through cooperation with NFAT. Cell. 2006;126(2):375-87.

49. Li S, Weidenfeld J, Morrisey EE. Transcriptional and DNA binding activity of the Foxp1/2/4 family is modulated by heterotypic and homotypic protein interactions. Mol Cell Biol. 2004;24(2):809-22.

50. Li B, Samanta A, Song X, lacono KT, Brennan P, Chatila TA, et al. FOXP3 is a homo-oligomer and a component of a supramolecular regulatory complex disabled in the human XLAAD/IPEX autoimmune disease. Int Immunol. 2007;19(7):825-35.

51. Kitoh A, Ono M, Naoe Y, Ohkura N, Yamaguchi T, Yaguchi $H$, et al. Indispensable role of the Runx1-Cbfbeta transcription complex for in vivosuppressive function of FoxP3+ regulatory T cells. Immunity. 2009;31(4):609-20.

52. Wu MS, Chen CJ, Lin JT. Host-environment interactions: their impact on progression from gastric inflammation to carcinogenesis and on development of new approaches to prevent and treat gastric cancer. Cancer Epidemiol Biomarkers Prev. 2005;14(8):1878-82.

53. Brunkow ME, Jeffery EW, Hjerrild KA, Paeper B, Clark LB, Yasayko SA, et al. Disruption of a new forkhead/winged-helix protein, scurfin, results in the fatal lymphoproliferative disorder of the scurfy mouse. Nat Genet. 2001;27(1):68-73.

54. Tone M, Greene MI. Cooperative regulatory events and Foxp3 expression. Nat Immunol. 2011;12(1):14-6.

55. Gao L, Li K, Li F, Li H, Liu L, Wang L, et al. Polymorphisms in the FOXP3 gene in Han Chinese psoriasis patients. J Dermatol Sci. 2010;57(1):51-6.

56. Nakanishi K, Shima Y. No contribution of a GT microsatellite polymorphism in the promoter region of the FOXP3 gene to susceptibility to type 1 diabetes in the Japanese population. Clin Chim Acta. 2007;384(1-2):171-3.

57. Raskin L, Rennert G, Gruber SB. FOXP3 germline polymorphisms are not associated with risk of breast cancer. Cancer Genet Cytogenet. 2009;190(1):40-2.

58. Zavattari P, Deidda E, Pitzalis M, Zoa B, Moi L, Lampis R, et al. No association between variation of the FOXP3 gene and common type 1 diabetes in the Sardinian population. Diabetes. 2004;53(7):1911-4.

59. Ferreira MA, McRae AF, Medland SE, Nyholt DR, Gordon SD, Wright MJ, et al. Association between ORMDL3, IL1RL1 and a deletion on chromosome 17q21 with asthma risk in Australia. Eur J Hum Genet. 2011;19(4):458-64.

60. Michel S, Liang L, Depner M, Klopp N, Ruether A, Kumar A, et al. Unifying candidate gene and GWAS Approaches in Asthma. PLoS One. 2010;5(11):e13894.

61. Torgerson DG, Ampleford EJ, Chiu GY, Gauderman WJ, Gignoux CR, Graves $P E$, et al. Meta-analysis of genome-wide association studies of asthma in ethnically diverse North American populations. Nat Genet. 2011;43(9):887-92.

62. Wise AL, Gyi L, Manolio TA. eXclusion: toward integrating the $X$ chromosome in genome-wide association analyses. Am J Hum Genet. 2013;92(5):643-7.

63. Abecasis GR, Auton A, Brooks LD, DePristo MA, Durbin RM, Handsaker RE, et al. An integrated map of genetic variation from 1,092 human genomes. Nature. 2012;491(7422):56-65.

64. Ross MT, Grafham DV, Coffey AJ, Scherer S, McLay K, Muzny D, et al. The DNA sequence of the human X chromosome. Nature. 2005;434(7031):325-37.

65. Moffatt MF, Gut IG, Demenais F, Strachan DP, Bouzigon E, Heath S, et al. A large-scale, consortium-based genomewide association study of asthma. N Engl J Med. 2010;363(13):1211-21.

66. Konig IR, Loley C, Erdmann J, Ziegler A. How to include chromosome X in your genome-wide association study. Genet Epidemiol. 2014;38(2):97-103.

67. Bottema RW, Kerkhof M, Reijmerink NE, Koppelman GH, Thijs C, Stelma FF, et al. X-chromosome Forkhead Box P3 polymorphisms associate with atopy in girls in three Dutch birth cohorts. Allergy. 2010;65(7):865-74.

68. Fodor E, Garaczi E, Polyanka H, Koreck A, Kemeny L, Szell M. The rs3761548 polymorphism of FOXP3 is a protective genetic factor against allergic rhinitis in the Hungarian female population. Hum Immunol. 2011;72(10):926-9.

69. Zhang L, Zhang Y, Desrosiers M, Wang C, Zhao Y, Han D. Genetic association study of FOXP3 polymorphisms in allergic rhinitis in a Chinese population. Hum Immunol. 2009;70(11):930-4.

70. Bottema RW, Kerkhof M, Reijmerink NE, Thijs C, Smit HA, van Schayck $C P$, et al. Gene-gene interaction in regulatory T-cell function in atopy and asthma development in childhood. J Allergy Clin Immunol. 2010;126(2):338-46. 346 e331-310.

71. Hassannia H, Abediankenari S, Ghaffari J. FOXP3 and TGF-beta gene polymorphisms in allergic rhinitis. Iran J Immunol. 2011;8(4):218-25. 
72. Zhang $Y$, Duan S, Wei X, Zhao Y, Zhao L, Zhang L. Association between polymorphisms in FOXP3 and EBI3 genes and the risk for development of allergic rhinitis in Chinese subjects. Hum Immunol. 2012;73(9):939-45.

73. Portela A, Esteller M. Epigenetic modifications and human disease. Nat Biotechnol. 2010;28(10):1057-68.

74. Rando OJ, Chang HY. Genome-wide views of chromatin structure. Annu Rev Biochem. 2009;78:245-71.

75. Tone Y, Furuuchi K, Kojima Y, Tykocinski ML, Greene MI, Tone M. Smad3 and NFAT cooperate to induce Foxp3 expression through its enhancer. Nat Immunol. 2008;9(2):194-202.

76. Baron U, Floess S, Wieczorek G, Baumann K, Grutzkau A, Dong J, et al. DNA demethylation in the human FOXP3 locus discriminates regulatory $T$ cells from activated FOXP3(+) conventional T cells. Eur J Immunol. 2007:37(9):2378-89

77. Floess S, Freyer J, Siewert C, Baron U, Olek S, Polansky J, et al. Epigenetic control of the foxp3 locus in regulatory T cells. PLoS Biol. 2007:5(2):e38.

78. Povoleri GA, Scotta C, Nova-Lamperti EA, John S, Lombardi G, Afzali B. Thymic versus induced regulatory $T$ cells - who regulates the regulators? Front Immunol. 2013:4:169.

79. Zheng Y, Josefowicz S, Chaudhry A, Peng XP, Forbush K, Rudensky AY. Role of conserved non-coding DNA elements in the Foxp3 gene in regulatory T-cell fate. Nature. 2010;463(7282):808-12.

80. Nadeau K, McDonald-Hyman C, Noth EM, Pratt B, Hammond SK, Balmes J, et al. Ambient air pollution impairs regulatory T-cell function in asthma. J Allergy Clin Immunol. 2010;126(4):845-52. e810

81. Brunst KJ, Leung YK, Ryan PH, Khurana Hershey GK, Levin L, Ji H, et al. Forkhead box protein 3 (FOXP3) hypermethylation is associated with diesel exhaust exposure and risk for childhood asthma. J Allergy Clin Immunol. 2013;131(2):592-4. e591-593.

82. Runyon RS, Cachola LM, Rajeshuni N, Hunter T, Garcia M, Ahn R, et al. Asthma discordance in twins is linked to epigenetic modifications of $\mathrm{T}$ cells. PLoS One. 2012;7(11):e48796.

83. Kohli A, Garcia MA, Miller RL, Maher C, Humblet O, Hammond SK, et al. Secondhand smoke in combination with ambient air pollution exposure is associated with increasedx CpG methylation and decreased expression of IFN-gamma in T effector cells and Foxp3 in T regulatory cells in children. Clin Epigenetics. 2012;4(1):17.

84. Lluis A, Depner M, Gaugler B, Saas P, Casaca VI, Raedler D, et al. Increased regulatory $T$-cell numbers are associated with farm milk exposure and lower atopic sensitization and asthma in childhood. J Allergy Clin Immunol. 2014;133(2):551-9

85. Michel S, Busato F, Genuneit J, Pekkanen J, Dalphin JC, Riedler J, et al. Farm exposure and time trends in early childhood may influence DNA methylation in genes related to asthma and allergy. Allergy. 2013;68(3):355-64.

86. Harb H, Raedler D, Ballenberger N, Bock A, Kesper DA, Renz H, et al. Childhood allergic asthma is associated with increased IL-13 and FOXP3 histone acetylation. J Allergy Clin Immunol. 2015;136(1):200-2.

87. Wu CJ, Yang CY, Chen YH, Chen CM, Chen LC, Kuo ML. The DNA methylation inhibitor 5 -azacytidine increases regulatory $T$ cells and alleviates airway inflammation in ovalbumin-sensitized mice. Int Arch Allergy Immunol. 2013;160(4):356-64.

\section{Submit your next manuscript to BioMed Central and take full advantage of:}

- Convenient online submission

- Thorough peer review

- No space constraints or color figure charges

- Immediate publication on acceptance

- Inclusion in PubMed, CAS, Scopus and Google Scholar

- Research which is freely available for redistribution 